\title{
Farms of Good Will in the Chynów municipality in the context of the Development Strategy of the Mazowieckie Voivodeship 2030
}

\section{Jacek Zalewski}

\section{Selected elements of the Development Strategy of the Mazowieckie Voivodeship 2030}

The vision adopted in the Strategy is that "Mazovia is a region characterized by territorial cohesion, competitiveness, innovativeness, rapid economic growth and high quality of life". The main goal is "reducing socio-economic disparities within the Mazovian region, increasing the role of the Warsaw metropolitan area in Europe". It is to be achieved through implementing the strategic goals, among which the one concerning social development is "Improving the quality of life and building a modern economy through making better use of humanand social capital".

The social development goal of the strategy is to be implemented through the following policy directions being adopted:

- Developing human and social capital,

- Developing the areas of science of key importance to the region,

- Providing equal educational opportunities,

- Activating the dormant assets of the labor market and improving the demographic situation,

- Making fuller use of human resources by increasing professional and spatial mobility,

- Combating social exclusion; social integration,

- Improving the functioning of social infrastructure; improving health care and public safety.

The policy direction concerning combating social exclusion is to be realized through the following recommended actions:

- Preventing unemployment and mitigating its effects,

- Preventing social marginalization of the disabled, older people and those in a difficult economic situation,

- Supporting actions leading to social inclusion and combating.

As far as improving the functioning of social infrastructure and improving health care and public safety are concerned, the recommended actions include developing social infrastructure, including infrastructure of regional importance.

The fifth section of the Strategy provides a detailed description of the policy directions. It includes the following statement: 
"Action is also necessary in order to prevent marginalization and contribute to the social inclusion of those at risk of being marginalized. The disabled should have access to better educational conditions, contributing to their integration. Support should also be provided to NGOs and other entities helping people in a difficult situation. (...) Children and teenagers should have access to daycare and activity facilities (including day rooms,social integration clubs, libraries, educational and after-school activity centers). Social inclusion should also be facilitated through social innovations which may also come in useful in other areas."

On March the 16th, 2015, the Mazovian Regional Assembly adopted the Regional Innovation Strategy for Mazovia 2020. The reasons for its adoption are specified in the introduction to the document:

"The Regional Innovation Strategy for Mazovia 2020 (RIS) is an elaboration on the Development Strategy of the Mazowieckie Voivodeship 2030. Mazovia as an Innovative Region (SRWM) and, specifically, the actions concerning increasing the competitiveness and innovativeness of the region. The RIS specifies the assumptions and goals of the regional innovation support system, oriented towards creating an environment favorable to enterprises' innovative activity.

The RIS contributes to the achievement of the primary strategic goal of the SRWM:

- Development of export-oriented production in the fields of medium and high-tech technology and the agri-food sector,

- $\quad$ as well as two other strategic goals:

- Increasing the region's competitivenessvia development of economic activity and transfer and implementation of new technologies and

- Improving the quality of life and building a modern economy through making better use of human and social capital".

Part 6 of the presents the vision in greater detail:

"The Development Strategy of the Mazowieckie Voivodeship 2030 presents a vision of Mazovia as an innovative region characterized by rapid economic growth. In line with these expectations, the Regional Innovation Strategy for Mazovia 2020 sees Mazovia in 2020 as:

- a strategic European center of research and development and business services,

- a highly innovative region with a networked economy integrated around the defined areas of smart specialization,

- a source of best practice in the field of social innovation.

The primary and strategic goals were chosen on the basis of several assumptions adopted when the RIS was being prepared [including]:

$[\ldots]$

- A high level of social capital and social trust is the basis for intensifying cooperation and increasing the tendency for social acceptance of new solutions and ideas, i.e. stimulating and developing innovative attitudes. Mazovia is characterized by a low level of social cohesion, hence particular attention should be paid to activities contributing to building social capital, including social trust and eliminating barriers to cooperation between various institutions. Support should be 
addressed to initiatives serving to integrate those active in the innovation market, including help in building cooperation networks and platforms of consensus. Attitudes contributing to cooperation should be promoted, along with initiatives stemming from cooperation between the region's economic entities.

- An effective tool for solving the region's social and economic problems may be the implementation of social innovations. Realizing new ideas for satisfying social needs contributes to creating new associations, developing cooperation and stimulating the activity of individual social entities. Therefore, social challenges should not be perceived as factors limiting economic development, but rather as a chance for innovations in the economy."

The document's operational goals include:

"Promoting attitudes and initiatives contributing to the initiation and implementation of social innovations in the region. Social innovations are one of the key tools to solving social problems. Stimulating activities in this area should stem from citizens' inventiveness, the activities of civil society organizations, local societies, enterprises and public institutions and services. Among the inhabitants and companies of Mazovia should be promoted all those activities and initiatives which are focused on initiating, implementing and developing new ideas (products, services, organizational models) in order to satisfy social needs and create new social relationships. On the local and regional level should be popularized those models of intersector cooperation which will shorten the time between an idea being born and its effective implementation."

A grassroots response to the goals specified in the Strategy is the Farm of Good Will. The undertaking is a novel approach to making use of the concepts of intelligent housing, universal design and sustainable construction in order to create a center where people with physical disabilities and the intellectually challenged will be able to find a home, aid from specialists and trainers along with work adapted to their capabilities in an ecological farm. The concept of the Farm of Good Will came from Jacek Zalewski from the village of Watraszew, the father of the disabled Kuba. The pillars of the project are the academic staff and student organizations of the Warsaw University of Technology and the Warsaw University of Life Sciences. The proposed farm is to be situated on plots situated in the Chynów municipality: 0.9 ha in the Janów village and 1.57 ha in the Watraszew village. The localization of Chynów next to main roads, railway lines and near an international airport, in the vicinity of the Warsaw agglomeration with several million inhabitants, provides a real opportunity for the implementation of a project in line with the Development Strategy of the Mazowieckie Voivodeship. 


\section{Premises of the project}

\section{Social technology}

People with disabilities appear in every society with equal probability, but not in all conditions are they equally likely to be able to survive, live and be happy. Statistics indicate that the disabled account for c. $14 \%$ of the society. Around $10 \%$ of this group are the intellectually challenged. The problems they have to deal with are usually present from the moment of birth and continue throughout one's life. The current solutions proposed for the intellectually challenged do not fully satisfy the parents, caretakers and specialists in the area. In Poland, significant funds are devoted to people with disabilities, but the activities undertaken are not cost-effective when the results are taken into account. A comparison with the solutions implemented in other countries suggests that at Poland's current stage of development, one may propose a significantly better approach. The activities addressed to a society's weakest members indicate its level of prosperity, culture and wisdom. If somebody cannot be healed, he should at least be happy - this is a new approach to permanently dependent persons.

The Farm of Good Will differs from existing nursing homes in that an individual approach is adapted to the needs of each of the inhabitants. The little homes are to be inhabited by a few people each, each one in their own room, equipped and furnished according to their individual needs and preferences. The innovativeness of the place stems from the use of new technologies which are to ensure the safety of the inhabitants, monitor their health and adjust the remaining parameters of the Farm, thus helping the caregivers and supporting staff.

\section{Safety}

Since 2016, parents and guardians have been telling the Farm's creators and builders about the specific behaviors and needs of its disabled future inhabitants through questionnaires and many hours of conversations. Turning on the water or light, opening windows and other, seemingly normal, everyday activities may pose a threat to the intellectually challenged and need to be continuously monitored. On the Farm, the effective functioning of most appliances will be controlled by previously programmed systems of intelligent controllers which are to prevent malfunctions and problems with usage. Spilling water, dropping inside temperature due to open windows, appliances left on will all be monitored by the safety system and be able to be controlled remotely or automatically turned off.

\section{Health}

The intellectually challenged are often unable to signal somatic complaints. Therefore, an important element of the Farm is an individual monitoring system of each inhabitant's 
physiological processes. It is to identify and register such things as epileptic seizures, body temperature, apnea, cardiac arrhythmia. Such information, transmitted immediately to the caretakers should result in a rapid reaction, i.e. first aid or calling for specialized medical aid.

The caretakers of dependent persons point to the need for the latter's place of residence to be monitored, as they can leave it, run away or hide, which may pose a threat to their health or even life. Hence, an inhabitant's current location will be monitored by electronic monitoring systems, along with such things as whether he is not leaving without permission or if somebody from outside has not entered the Farm's area. Such systems are to replace physical fences separating the Farm from the rest of the world. This should, according to many, provide the place with an open character and contribute to safe integration.

Among the activities planned to be realized in the Farm are also rehabilitation and medical aid addressed to its inhabitants and the local society (the Farm will function as a medical clinic with a public health services contract). In a few years, it should become a specialized medical care center for people with linked problems, i.e. neurological movement disorders or oncological neurological disorders. People with mental disabilities often require the care and cooperation of specialists in various fields: medicine, psychology, education of the mentally handicapped, etc. Hospitals, such as the Children's Memorial Health Institute, have a comprehensive enough structure, but are limited to providing care to children. In Central Europe there are no institutions which would provide complex care to adults with complex linked chronic diseases, i.e. ones with a genetic background. There is a need for such an institution. It could serve not only its primary group of patients, but also other inhabitants of the region.

\section{Work}

An often observed phenomenon in nursing homes is boredom and a lack of activity on the part of its inhabitants. An analysis of the capabilities and preferences of the inhabitants of the Farm will allow for various professional activities to be provided. Under the control of trainers and caretakers, the disabled will be active in the field of farming: taking care of animals, cultivating and processing fruits and vegetables; they will work in services such as laundry, sewing, minor repairs, catering; they will handcraft and produce everyday items, roast, ground and pack coffee, etc. The primary goal of such activities will be satisfaction and happiness of the dependent persons, stemming from a sense of personal agency and social usefulness. They are also to provide an additional source of income. There will also be provided the possibility of participating in apprenticeships and internships, as well as thematic conferences, for those interested in a given field of activity.

The number of inhabitants of the first Farm of Good Will in the Chynów municipality near Warsaw is supposed to be 30, including both the intellectually challenged and the staff. The Farm is to function as a Non-Public Nursing Home, a Center for People with Special Needs Providing Occupational Therapy Workshops and a Vocational Activation Center. All 
these forms are the basis for government financing. As a pilot program, the project has the potential to develop into various types of care. The proposed solutions will necessarily be verified as the project proceeds.

The conception stage has shown that making use of the existing capabilities of electronics, computers, etc., can provide a breakthrough in the way people with disabilities and the mentally challenged are treated. The Farm of Good Will has aroused significant interest in the modern technology sector, as such technologies may in the near future be used on a much broader scale. The Farm's potential also stems from the opportunities it will provide for studying the phenomena occurring in the environment of dependent persons, their mutual relationships and contacts with the local society. This will benefit students, scientists, psychologists, those active in the fields of social and medical sciences, employees of scientific institutes and other research institutions.

The care for the permanently dependent will soon be subject to revolutionary changes thanks to artificial intelligence, modern technology and passive housing. The Farm of Good Will will be their "first swallow" (Fig. 1, 2).

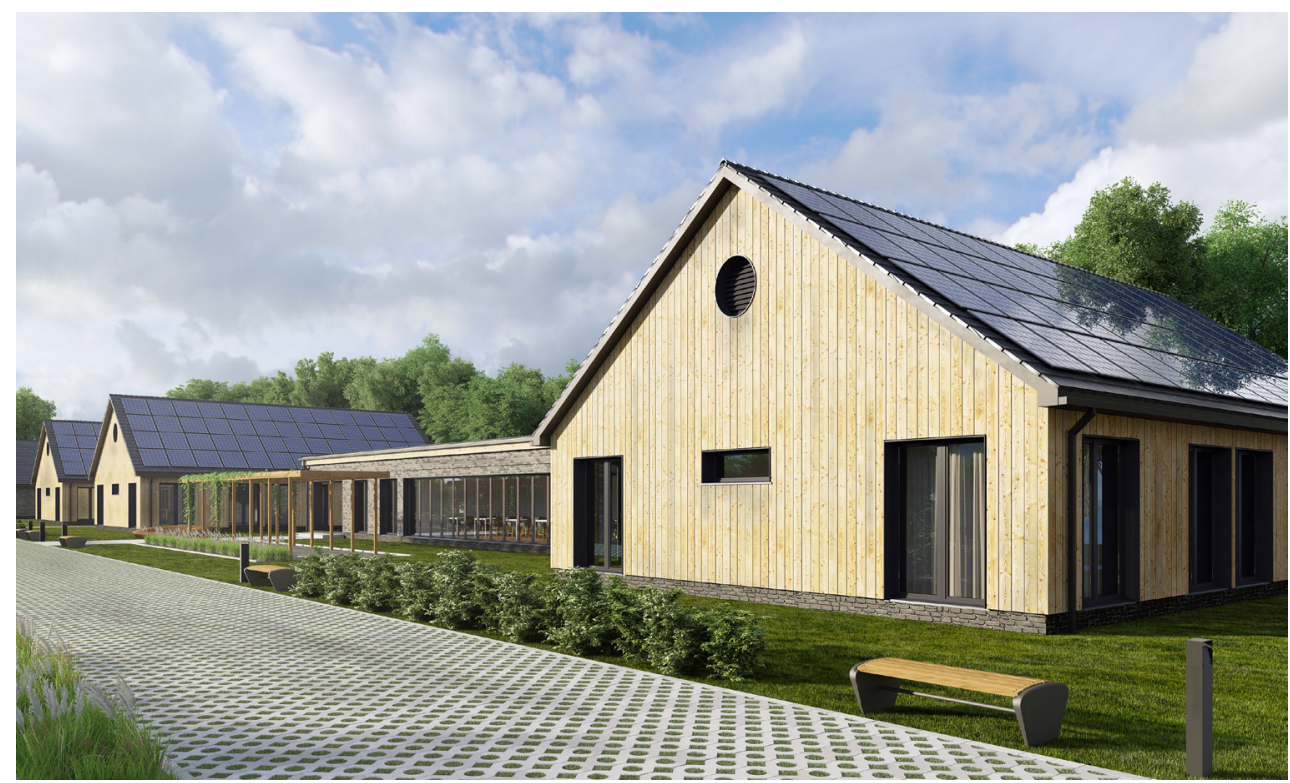

Fig. 1. The Farm project

Source: author's archive 


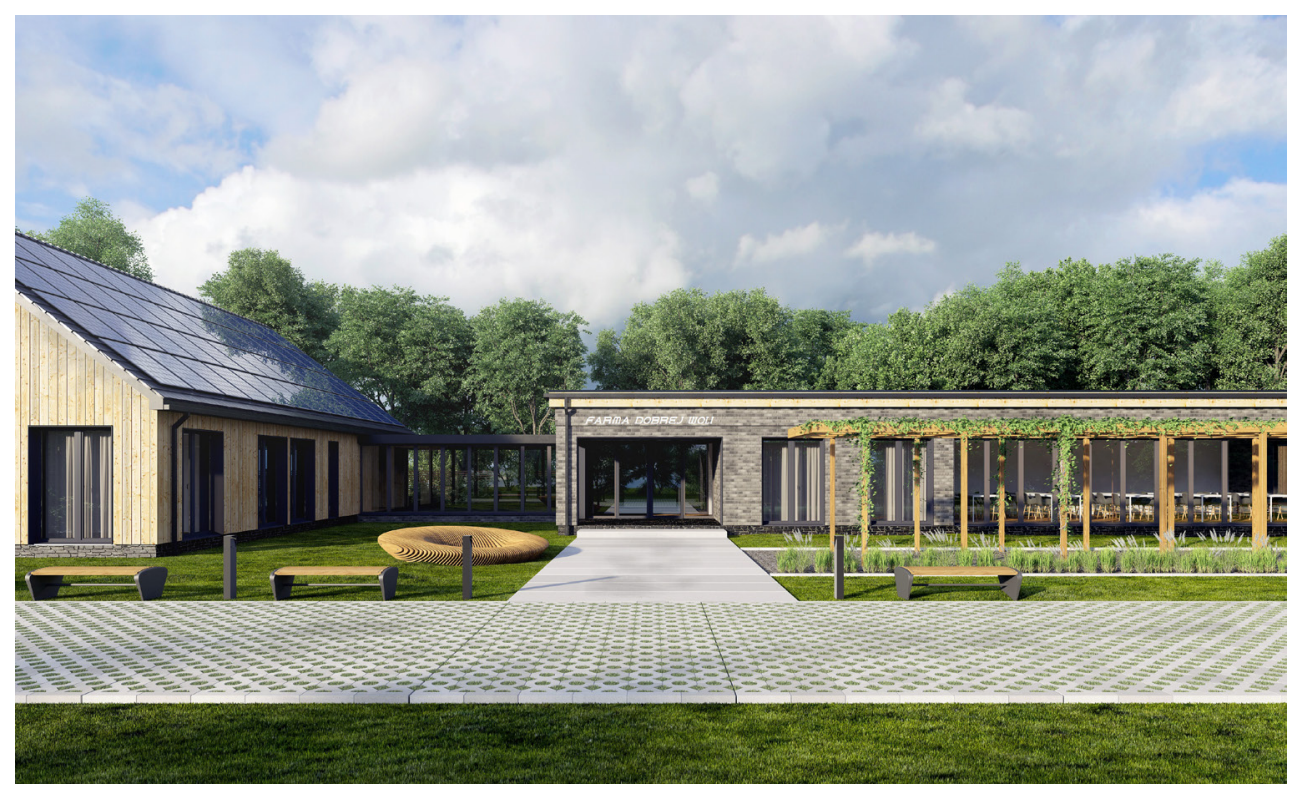

Fig. 2. The Farm project

Source: author's archive

Jacek Zalewski, MSc - lives in Watraszew. He is a Knight of the Order of the Smile, an advisor to the Minister of Labor and Social Policy, the chairman of the Mazovian Community Council for the Disabled, the president of the Good Will public benefit association. He is the author of numerous publications concerning system solutions to the problems of groups at risk of social exclusion. He is the father of the disabled Kuba. Before his son's birth, he was employed on executive positions in commercial companies.E-mail:jzal@poczta.onet.pl

Jacek Zalewski, mgr - mieszka Watraszewie, Kawaler Orderu Uśmiechu, Doradca Ministra Pracy i Polityki Społecznej, Przewodniczący Mazowieckiej Społecznej Rady ds. Osób Niepełnosprawnych, Prezes Stowarzyszenia Dobra Wola OPP. Autor licznych publikacji dotyczących rozwiqzań systemowych dla grup zagrożonych wykluczeniem społecznym. Ojciec niepełnosprawnego Kuby. Przed urodzeniem syna pracował na stanowiskach kierowniczych w spółkach prawa handlowego.

E-mail:jzal@poczta.onet.pl 